\title{
Predictors for Metachronous Metastases in Early Breast Cancer: A Single Institution Study
}

\author{
Haytham Mahmoud Awad Fayed ${ }^{*}$, Mohamed Ali Abdalla Billel1, \\ Galal Mostafa Abouelnagah1, Gehan A. Khedr²
}

\begin{abstract}
${ }^{1}$ Surgical Oncology Department, Alexandria Faculty of Medicine, Alexandria University, Alexandria, Egypt ${ }^{2}$ Clinical Oncology Department, Alexandria Faculty of Medicine, Alexandria University, Alexandria, Egypt Email: ${ }^{\star h}$ aytham.fayed@alexmed.edu.eg
\end{abstract}

How to cite this paper: Fayed, H.M.A., Billel, M.A.A., Abouelnagah, G.M. and Khedr, G.A. (2021) Predictors for Metachronous Metastases in Early Breast Cancer: A Single Institution Study. Advances in Breast Cancer Research, 10, 87-99.

https://doi.org/10.4236/abcr.2021.103007

Received: December 28, 2020

Accepted: July 12, 2021

Published: July 15, 2021

Copyright $\odot 2021$ by author(s) and Scientific Research Publishing Inc. This work is licensed under the Creative Commons Attribution International License (CC BY 4.0).

http://creativecommons.org/licenses/by/4.0/

\begin{abstract}
Background: Breast cancer (BC) is considered the most common women cancer worldwide. The main clinicopathological prognostic factors are tumor size, lymph node status and estrogen/progesterone (ER/PR) receptor status. In addition, some factors are both prognostic and predictive as ER/PR receptors and HER2/neu overexpression. Axillary lymph node status is the most important prognostic factor for breast cancer. Node negative breast cancer patients had the best 5 -year overall survival (OS) of $82.8 \%$ compared to $73 \%$, $45.7 \%$, and $28.4 \%$ for patients with $1-3,4-12$, and $\geq 13$ positive nodes, respectively. The aim of this study was to determine the association between different clinicopathological features and development of metastasis in a group of Egyptian women with early breast cancer, also, to assess patients' Relapse-free survival (DFS) and OS and their correlation with different clinicopathological features. Patients and Methods: We retrospectively reviewed the files of breast cancer patients who were treated and followed-up at the clinical oncology department and surgical oncology unit, Alexandria Main University Hospital during the period from January 2014 to December 2017. A total of 1848 breast cancer cases were presented during this period of time. 141 out of the 1848 patients developed metastasis from breast cancer during follow-up. Among the 141 patients, only 102 had adequate clinical, pathological, treatment and follow-up data enough for analysis and were included in our study. Results: The number of patients who developed distant metastasis from breast cancer during the study period (metachronous metastasis) ranges from 17 - 31 cases/year. All the study patients had documented metastatic disease constituting 102 out of 1848 collected patients representing about $5.5 \%$. The median time for development of metastasis from the initial diagnosis among the 102 studied patients was 17.88 months. Seventy-two out of 102 cases had distant recurrence. There was a significant correlation between
\end{abstract}


DFS and tumor size, grade, number of lymph nodes involved and hormone receptor (ER and PR) status. Age, tumor grade, tumor size and Her2 status had a significant impact on the OS. Conclusion: The clinicopathological characteristics of the primary tumor are important for predicting the risk of metastasis among early breast cancer patients and determining their prognosis.

\section{Keywords}

Breast Cancer, Metastasis, Relapse Free Survival, Overall Survival

\section{Introduction}

Breast cancer (BC), is the most common cancer in women worldwide [1]. At the time of diagnosis, $49.7 \%$ of Egyptian female breast cancer patients have regional metastasis and $11.7 \%$ have distant metastasis [2]. The known breast cancer prognostic factors include tumor size, lymph node status and estrogen/progesterone receptor (ER/PR) status. Some factors are both prognostic and predictive, such as HER2/neu overexpression and hormone receptor status [3]. Axillary lymph node metastasis is the most important prognostic factor for breast cancer. Studies have shown that distant recurrence risk is being directly associated with the presence and extent of the axillary lymph node involvement [4] [5] [6] [7]. Node negative breast cancer patients had the best 5-year overall survival of $82.8 \%$ compared to 1 - 3 positive nodes with $73 \%, 4-12$ positive nodes with $45.7 \%$, and $\geq 13$ positive nodes with $28.4 \%$ [7]. The prognosis of young patients is worse as compared to elderly breast cancer patients. Several studies have shown that tumor histological grade is one of the breast cancer prognostic factors [8] [9] [10]. ER/PR positive tumors have better survival than the ER/PR negative ones [11]. Nottingham prognostic index (NPI) is a prognostic tool based on the following three parameters: tumor diameter, lymph node status and tumor grade [12]. NPI is used in predicting risks of recurrence from breast cancer and its significance has been validated in several studies [13] [14] [15]. In recent years, another version has been developed known as Nottingham prognostic index plus (NPI+). NPI+ is based on the well-established clinicopathological parameters used in the NPI but has been refined to integrate tumor biological factors such as ER, PR, and different cytokeratins [16]. Some studies have also shown that molecular subtypes of breast cancer have different survival outcomes and unique patterns of metastasis [17].

Distant recurrence is diagnosed when non-metastatic breast cancer patient develops distant metastasis during or after completion of treatment. Distant Metastasis from breast cancer is defined by tumor spread beyond the breast, chest wall, and regional lymph nodes [18]. The common sites for breast cancer metastasis include bone, lung, brain, liver and distant lymph nodes [18]. Bone is the most common site of metastasis, as it has been observed in most studies [19] 


\section{[20].}

\section{Aim of the Study}

The aim of this study was to determine the association between different clinicopathological features and development of metastasis in a group of Egyptian women with early breast cancer. Also, to assess patients' DFS and OS and their correlation with different clinicopathological features.

\section{Materials and Methods}

We retrospectively reviewed the medical records of breast cancer patients who were treated and followed-up at the clinical oncology department and surgical oncology unit, Alexandria main university hospital during the period from January 2014 to December 2017. A total of 1848 breast cancer cases were presented during this period of time. 141 out of the 1848 patients developed metachronous metastasis during follow-up after treatment of their early breast cancer. Among the 141 patients, only 102 had adequate clinical, pathological, treatment and follow-up data enough for analysis and were included in our study. Patients who had metastatic breast cancer at initial presentation as well as patients who continued to be free from relapse during follow up were excluded from the study. Variables obtained from the registry included: patient profile and history; age at diagnosis, family history, menopausal status, BMI, date of diagnosis and date of recurrence. Also, we collected data about tumor characteristics as tumor size, side, site, lymph node involvement, histological type, tumor grade, estrogen receptor, progesterone receptor, human epidermal growth factor receptor -2 (HER-2) receptor status and Ki 67. In addition, we collected data about treatments received including date and type of breast surgery (mastectomy or BCS), axillary surgery (sentinel lymph node biopsy or axillary lymph node dissection), chemotherapy (type and number of cycles), radiotherapy (dose and fractionation), targeted therapy and hormonal therapy (type and duration of treatment). The pattern of metastasis including sites (bone, visceral or both), numbers of metastatic sites, and date of relapse as well as rebiopsy results if done were retrieved.

\section{Statistical analysis of the data}

Data were fed to the computer and analyzed using IBM SPSS software package version 20.0. (Armonk, NY: IBM Corp) Qualitative data were described using number and percent. Quantitative data were described using range (minimum and maximum), mean, standard deviation and median. Significance of the obtained results was judged at the $5 \%$ level. DFS is defined as the period from surgery till recurrence. OS is defined as the period from date of diagnosis till death or last follow up.

\section{Results}

The number of cases who developed distant metastasis from breast cancer dur- 
ing study period (metachronous metastasis) ranges from 17 - 31 cases/year. Total number of cases involved in the study analysis was 102, accounting for $5.5 \%$ of the 1848 total breast cancer cases presented in the same years. Patients' age ranged from 25 to 85 years with a mean age of $48.77 \pm 10.72 .63 .7 \%$ patients aged between 40 - 60 years, while $23.5 \%$ and $12.7 \%$ patients aged between $20-40$ years and $>60$ years, respectively. Patients' mean weight was $79.77 \pm 14.49$, median weight was $80 \mathrm{~kg}$, mean height was $159.56 \mathrm{~cm} \pm 8.97$ and median height was $159 \mathrm{~cm}$. The BMI ranged from $17.36 \mathrm{~kg} / \mathrm{m}^{2}$ to $50.78 \mathrm{~kg} / \mathrm{m}^{2}$, with a mean of $31.50 \pm 6.08$ and a median of $31.25 \mathrm{~kg} / \mathrm{m}^{2}$.

The most common chemotherapy regimen received was FAC (fluorouracil, Adriamycin and cyclophosphamide) in both neoadjuvant and adjuvant setting. Neoadjuvant chemotherapy was given to 13 (12.7\%) cases and FAC was the most common regimen administered to $61.5 \%$ of the 13 cases. While adjuvant chemotherapy was given to $89(87.3 \%)$ remaining cases and FAC was the most common regimen administered to $55.1 \%$ of the 89 cases.

Adjuvant hormonal therapy was administered to 60 patients $(58.8 \%)$. The most common hormonal treatment used was tamoxifen given to 51 cases which constituted $85 \%$ of the total cases receiving hormonal therapy. Letrozole and anastrozole were administered to $10 \%(\mathrm{n}=6)$ and $1.7 \%(\mathrm{n}=1)$ of the total cases receiving hormonal therapy respectively and the remaining $3.3 \%(\mathrm{n}=2)$ received tamoxifen and then switched to anastrozole.

Adjuvant herceptin was administered to 11 patients (10.8\%). The total duration of adjuvant herceptin ranged from 2 - 12 months with a median of 8 months.

Loco-regional radiotherapy was administered to 83 patients $(81.4 \%)(\mathrm{n}=83)$. The most common dose of radiotherapy was $45 \mathrm{~Gy}$ in 22 fractions given to $68.7 \%(\mathrm{n}=57 / 83$ patients receiving radiotherapy). While $26 / 83$ (31.3\%) patients received hypofractionated radiotherapy $40.5 \mathrm{~Gy}$ in 15 fractions.

The median time of recurrence from the initial treatment among the 102 total cases was 17.88 months. $70.6 \%$ patients (72 out of 102) had distant recurrence upon relapse. Some patients developed local recurrence only initially then developed distant metastasis later, they constituted $15.7 \%$. Other patients (13.7\%) had both local and distant recurrence. The most common site for metastasis was bone which was observed in $74.5 \%$ patients $(76 / 102)$.

Upon relapse, 51 patients (50\%) received hormonal treatment and $43.1 \%$ of them received letrozole. Only 7 cases $(6.9 \%)$ received herceptin at relapse. Palliative surgery was performed in only 8 cases $(7.8 \%)$. Chemotherapy was given to $64.7 \%(\mathrm{n}=66)$ and $43.9 \%(29 / 66$ patients $)$ received taxanes. $58.8 \%(\mathrm{n}=60)$ of the total cases received palliative radiotherapy.

Among 102 study patients, $71.6 \%$ died during treatment or follow up and the remaining $28.4 \%$ were alive by the time data was taken.

Figure 1 shows that there was significant correlation between DFS and tumor size, grade, number of lymph nodes involved and hormone receptor (ER and PR) status. Table 1 and Table 2 show the Correlation between clinicopathological characteristics and DFS. In our study, number of involved lymph nodes was 

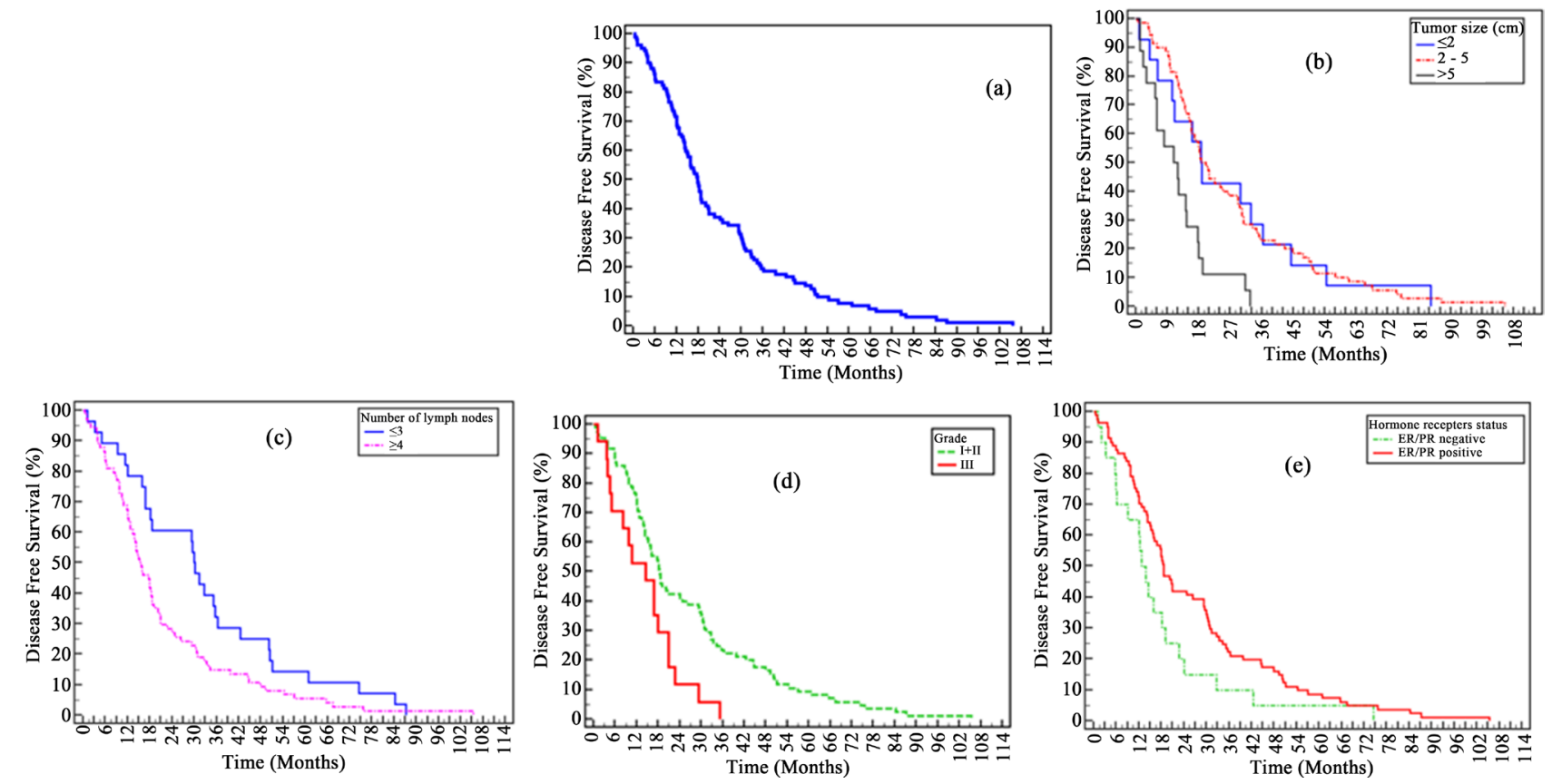

Figure 1. (a) Kaplan-Meier survival curve for disease free survival. (b) Kaplan-Meier survival curvefor disease free survival for tumor size. (c) Kaplan-Meier survival curve for disease free survival for number of lymph nodes involved. (d) Kaplan-Meier survival curve for disease free survival for tumor grade. (e) Kaplan-Meier survival curve for disease free survival for hormone receptor status.

Table 1. Correlation between clinicopathological characteristics and DFS.

\begin{tabular}{|c|c|c|c|c|c|c|c|c|}
\hline Disease free survival & Mean & Median & $\begin{array}{c}1 \\
\text { year \% }\end{array}$ & $\begin{array}{c}2 \\
\text { year \% }\end{array}$ & $\begin{array}{c}5 \\
\text { year \% }\end{array}$ & $\begin{array}{l}\text { End of } \\
\text { the study }\end{array}$ & $x^{2}$ & $\mathrm{p}$ \\
\hline \multicolumn{9}{|l|}{ Age } \\
\hline $20-40$ & 19.0 & 15.9 & 66.7 & 33.3 & 0.0 & 0.0 & \multirow{3}{*}{3.360} & \multirow{3}{*}{0.186} \\
\hline$>40-60$ & 25.4 & 18.4 & 76.9 & 36.9 & 9.2 & 0.0 & & \\
\hline$>60$ & 30.2 & 12.2 & 53.8 & 46.2 & 15.4 & 0.0 & & \\
\hline \multicolumn{9}{|l|}{ BMI } \\
\hline$<25$ & 19.8 & 13.9 & 55.6 & 33.3 & 11.1 & 0.0 & \multirow{2}{*}{0.041} & \multirow{2}{*}{0.840} \\
\hline$>25$ & 20.8 & 15.8 & 69.4 & 29.0 & 4.8 & 0.0 & & \\
\hline \multicolumn{9}{|l|}{ Menopausal status } \\
\hline Pre & 20.7 & 16.8 & 66.0 & 31.9 & 4.3 & 0.0 & \multirow{2}{*}{3.055} & \multirow{2}{*}{0.080} \\
\hline Post & 27.9 & 18.7 & 75.9 & 42.6 & 11.1 & 0.0 & & \\
\hline \multicolumn{9}{|l|}{ Histological type } \\
\hline Lobular & 22.6 & 26.4 & 80.0 & 60.0 & - & 0.0 & \multirow{2}{*}{0.080} & \multirow{2}{*}{0.777} \\
\hline Ductal & 24.6 & 17.8 & 71.1 & 36.1 & 8.2 & 0.0 & & \\
\hline \multicolumn{9}{|l|}{ Grade } \\
\hline Grade $1+2$ & 26.5 & 18.4 & 75.3 & 42.4 & 9.4 & 0.0 & \multirow{2}{*}{$7.648^{*}$} & \multirow{2}{*}{$0.006^{*}$} \\
\hline Grade 3 & 14.2 & 14.5 & 52.9 & 11.8 & - & 0.0 & & \\
\hline \multicolumn{9}{|l|}{ Tumor size $(\mathrm{cm})$} \\
\hline$\leq 2$ & 26.3 & 18.7 & 64.3 & 42.9 & 7.1 & 0.0 & $15.059^{*}$ & $0.001^{*}$ \\
\hline
\end{tabular}


Continued

\begin{tabular}{|c|c|c|c|c|c|c|c|c|}
\hline $2-5$ & 27.4 & 18.7 & 78.6 & 42.9 & 10.0 & 0.0 & & \\
\hline$>5$ & 12.0 & 10.7 & 50.0 & 11.1 & 0.0 & 0.0 & & \\
\hline \multicolumn{9}{|c|}{ Lymph node involvement } \\
\hline Negative & 34.5 & 31.3 & 75.0 & 68.8 & 18.8 & 0.0 & \multirow{2}{*}{3.114} & \multirow{2}{*}{0.078} \\
\hline Positive & 22.6 & 16.1 & 70.9 & 31.4 & 5.8 & 0.0 & & \\
\hline \multicolumn{9}{|c|}{ Number of lymph nodes } \\
\hline$\leq 3$ & 32.9 & 29.9 & 82.1 & 60.7 & 14.3 & 0.0 & \multirow{2}{*}{$5.046^{*}$} & \multirow{2}{*}{$0.025^{\star}$} \\
\hline$\geq 4$ & 21.3 & 15.3 & 67.6 & 28.4 & 5.4 & 0.0 & & \\
\hline \multicolumn{9}{|l|}{ HER-2 status } \\
\hline Negative & 26.2 & 18.4 & 70.1 & 41.8 & 8.9 & 0.0 & \multirow{2}{*}{2.365} & \multirow{2}{*}{0.124} \\
\hline Positive & 20.2 & 14.5 & 72.7 & 27.3 & 3.3 & 0.0 & & \\
\hline \multicolumn{9}{|c|}{ Hormone receptors status } \\
\hline ER/PR negative & 17.4 & 12.8 & 65.0 & 20.0 & 5.0 & 0.0 & \multirow{2}{*}{$3.833^{*}$} & \multirow{2}{*}{$0.049^{*}$} \\
\hline ER/PR positive & 26.3 & 18.7 & 72.8 & 42.0 & 8.6 & 0.0 & & \\
\hline \multicolumn{9}{|c|}{ Lymph vascular invasion } \\
\hline Negative & 15.6 & 11.7 & 46.2 & 23.1 & 7.6 & 0.0 & \multirow{2}{*}{0.133} & \multirow{2}{*}{0.715} \\
\hline Positive & 19.6 & 15.8 & 69.4 & 25.8 & 0.0 & 0.0 & & \\
\hline
\end{tabular}

Table 2. Cox regression analysis for DFS.

\begin{tabular}{ccccc}
\hline & \multicolumn{2}{c}{ Univariate } & \multicolumn{2}{c}{${ }^{*}$ Multivariate } \\
\cline { 2 - 5 } & $\mathbf{p}$ & OR (95\%C.I) & $\mathbf{p}$ & OR (95\%C.I) \\
\hline Grade & $0.007^{*}$ & $2.115(1.228-3.642)$ & $0.027^{*}$ & $1.875(1.076-3.267)$ \\
Tumor size (cm) & $0.014^{*}$ & $1.715(1.117-2.631)$ & 0.144 & $1.392(0.894-2.168)$ \\
Number of lymph nodes & $0.007^{*}$ & $1.342(1.085-1.660)$ & $0.020^{*}$ & $1.282(1.039-1.580)$ \\
Hormone receptors status & $0.048^{*}$ & $1.064(1.002-3.920)$ & 0.093 & $0.651(0.394-1.075)$ \\
\hline
\end{tabular}

OR: Odd's ratio, C.I: Confidence interval, \#: All variables with $\mathrm{p}<0.05$ were included in the multivariate. *: Statistically significant at $\mathrm{p} \leq 0.05$

found to have a significant impact on DFS. Equal or more than 4 lymph nodes involved was associated with shorter DFS $(n=71)$ than those with $<4$ axillary lymph nodes $(\mathrm{n}=31)$. Median DFS among patients with $\geq 4$ axillary lymph nodes was 15.3 months, compared to 29.9 months among patients with $<4$ axillary lymph nodes. $(\mathrm{p}=0.025)$.

Table 1 shows correlation between different clinicopathological characteristics and DFS.

The 1, 2 and 5-year overall survival rates (Table 3) for our patients were 96\%, $68.9 \%$ and $31.5 \%$ respectively, while the median survival time was 37.9 months (Figure 2(a)).

In our study (Table 3 and Table 4), age was found to have a significant impact on overall survival. Better survival was seen to be associated with increased age. 
Table 3. Correlation between clinicopathological characteristics and OS.

\begin{tabular}{|c|c|c|c|c|c|c|c|c|}
\hline Overall Survival & Mean & Median & $\begin{array}{c}1 \text { year } \\
\%\end{array}$ & $\begin{array}{c}2 \text { year } \\
\%\end{array}$ & $\begin{array}{c}5 \\
\text { year \% }\end{array}$ & $\begin{array}{l}\text { End of } \\
\text { the study }\end{array}$ & $x^{2}$ & $\mathrm{p}$ \\
\hline \multicolumn{9}{|l|}{ Age } \\
\hline $20-40$ & 34.5 & 37.2 & 95.8 & 60.7 & 15.7 & 7.8 & \multirow{3}{*}{$6.056^{*}$} & \multirow{3}{*}{$0.048^{*}$} \\
\hline$>40-60$ & 46.5 & 38.6 & 96.9 & 66.3 & 31.5 & 0.0 & & \\
\hline$>60$ & 69.1 & 79.8 & 91.7 & 91.7 & 58.9 & 19.6 & & \\
\hline \multicolumn{9}{|l|}{ BMI } \\
\hline$<25$ & 31.7 & 24.9 & 88.9 & 55.6 & 14.8 & 0.0 & \multirow{2}{*}{2.117} & \multirow[b]{2}{*}{0.146} \\
\hline$>25$ & 45.2 & 37.2 & 96.8 & 66.5 & 30.8 & 0.0 & & \\
\hline \multicolumn{9}{|l|}{ Menopausal status } \\
\hline Pre & 38.5 & 37.2 & 93.6 & 63.8 & 16.7 & 0.0 & \multirow{2}{*}{3.580} & \multirow[b]{2}{*}{0.058} \\
\hline Post & 55.1 & 42.9 & 98.1 & 72.7 & 43.9 & 0.0 & & \\
\hline \multicolumn{9}{|l|}{ Histological type } \\
\hline Lobular & 30.0 & 30.9 & 100 & 100 & - & 25.0 & \multirow{2}{*}{0.006} & \multirow{2}{*}{0.939} \\
\hline Ductal & 48.1 & 37.9 & 95.8 & 67.5 & 32.0 & 0.0 & & \\
\hline \multicolumn{9}{|l|}{ Grade } \\
\hline Grade $1+2$ & 50.8 & 41.2 & 96.5 & 71.7 & 35.7 & 0.0 & \multirow{2}{*}{$5.429^{*}$} & \multirow{2}{*}{$0.020^{*}$} \\
\hline Grade 3 & 28.6 & 30.7 & 93.3 & 53.3 & - & 0.0 & & \\
\hline \multicolumn{9}{|l|}{ Tumor size $(\mathrm{cm})$} \\
\hline$\leq 2$ & 45.8 & 39.4 & 100 & 77.4 & 37.1 & 0.0 & \multirow{3}{*}{$13.331^{*}$} & \multirow{3}{*}{$0.001^{*}$} \\
\hline $2-5$ & 52.9 & 41.7 & 95.7 & 76.1 & 36.1 & 0.0 & & \\
\hline$>5$ & 24.6 & 21.1 & 94.1 & 35.3 & 0.0 & 0.0 & & \\
\hline \multicolumn{9}{|c|}{ Lymph node involvement } \\
\hline Negative & 52.7 & 45.7 & 93.8 & 73.7 & 38.3 & 0.0 & \multirow{2}{*}{0.167} & \multirow{2}{*}{0.682} \\
\hline Positive & 45.1 & 37.2 & 96.5 & 68.0 & 30.4 & 3.6 & & \\
\hline \multicolumn{9}{|c|}{ Number of lymph nodes } \\
\hline$\leq 3$ & 50.2 & 37.7 & 96.4 & 70.5 & 39.3 & 0.0 & \multirow{2}{*}{0.126} & \multirow{2}{*}{0.723} \\
\hline$\geq 4$ & 44.9 & 37.9 & 95.9 & 68.2 & 27.4 & 5.3 & & \\
\hline \multicolumn{9}{|l|}{ HER-2 status } \\
\hline Negative & 54.4 & 42.9 & 97.0 & 73.8 & 39.4 & 0.0 & \multirow{2}{*}{$5.312^{*}$} & \multirow{2}{*}{$0.021^{*}$} \\
\hline Positive & 36.2 & 28.3 & 93.7 & 59.3 & 18.7 & 0.0 & & \\
\hline Hormone receptors & atus & & & & & & & \\
\hline ER /PR negative & 38.7 & 30.7 & 94.7 & 63.2 & 23.1 & 0.0 & & \\
\hline ER/PR positive & 50.4 & 39.4 & 96.2 & 71.0 & 34.1 & 0.0 & 1.596 & 0.207 \\
\hline Lymph vascular in & & & & & & & & \\
\hline Negative & 30.0 & 25.5 & 100 & 55.6 & 32.9 & 22.2 & & \\
\hline Positive & 37.4 & 31.4 & 93.3 & 60.9 & 24.9 & 5.1 & 0.030 & 0.700 \\
\hline
\end{tabular}



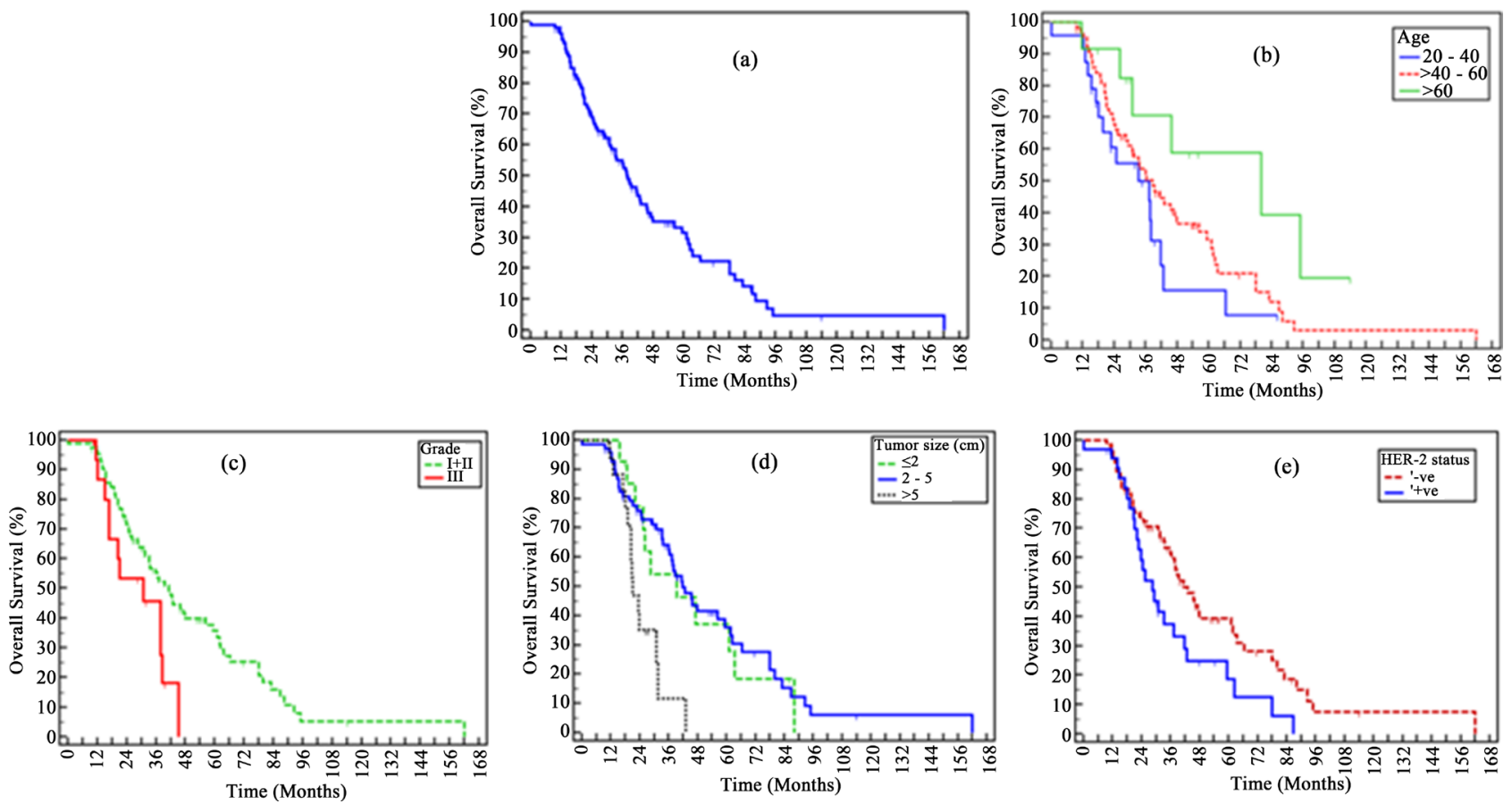

Figure 2. (a) Kaplan-Meier survival curve for overall survival. (b) Kaplan-Meier survival curve for overall survival for age. (c) Kaplan-Meier survival curve for overall survival for tumor grade. (d) Kaplan-Meier survival curve for overall survival for tumor size. (e) Kaplan-Meier survival curve for overall survival for Her2 receptor status.

Table 4. Cox regression analysis for overall survival.

\begin{tabular}{ccccc}
\hline & \multicolumn{2}{c}{ Univariate } & \multicolumn{2}{c}{${ }^{*}$ Multivariate } \\
\cline { 2 - 5 } & $\mathrm{p}$ & OR $(95 \%$ C.I $)$ & $\mathrm{p}$ & OR (95\% C.I) \\
\hline Age & $0.015^{*}$ & $0.601(0.399-0.907)$ & $0.031^{*}$ & $0.617(0.398-0.956)$ \\
Grade & $0.023^{*}$ & $2.122(1.110-4.057)$ & $0.049^{*}$ & $1.951(1.00-3.806)$ \\
Tumor size (cm) & $0.030^{*}$ & $1.745(1.056-2.881)$ & $0.036^{*}$ & $1.791(1.038-3.092)$ \\
HER-2 status & $0.022^{*}$ & $1.634(1.075-2.485)$ & $0.045^{*}$ & $1.551(1.011-2.381)$ \\
\hline
\end{tabular}

OR: Odd's ratio, C.I: Confidence interval, \#: All variables with $\mathrm{p}<0.05$ was included in the multivariate. *: Statistically significant at $\mathrm{p} \leq 0.05$.

Median OS among patients older than 60 years $(\mathrm{n}=13)$ of age was 79.8 months, compared to age group of $>40-60$ years $(n-65)$ and $20-40$ years $(n=24)$ having 38.6 months and 37.2 months respectively $(\mathrm{p}=0.048)$ (Figure $2(\mathrm{~b})$ ). In addition, tumor grade had a significant impact on overall survival. Low grade tumors (grade 1 and 2) had better OS than high grade tumors (grade 3). Table 4 shows factors that affect the OS. Median OS was 41.2 months and 30.7 months for patients with low grade and high grade tumors, respectively $(\mathrm{p}=0.020)$ (Figure $2(c))$. Tumor size had also significant impact on OS, poor survival was associated with larger tumor size. Median OS among patients with tumor size of $>5$ $\mathrm{cm}(\mathrm{n}=18)$ was 21.1 months, compared to 41.7 months and 39.4 months for patients with tumor size of $>2-5 \mathrm{~cm}(\mathrm{n}=70)$ and $<2 \mathrm{~cm}(\mathrm{n}=14)$, respectively $(\mathrm{p}=$ 0.001 ) (Figure $2(\mathrm{~d})$ ). HER2/neu status was found to have a significant impact on 
overall survival. Better survival was seen to be associated with HER2/neu negative $(n=33)$ than HER2/neu positive $(n=69)$ tumors. Median OS among patients with HER2/neu negative was 54.4 months, compared to 36.2 months among the patient with HER2/neu positive $(\mathrm{p}=0.021)$ (Figure $2(\mathrm{e})$ ).

\section{Discussion}

Distant recurrence is the most common form of recurrence after surgery and can occur either during or after completion of treatment [21] [22]. The median age among Egyptian breast cancer patients tends to be younger than that of western countries [2]. Some studies have shown that premenopausal women have better survival than postmenopausal patients [23]. This finding was not confirmed in our study and the effect of the menopausal status on survival was not significant. Tumor size and lymph nodes status are important prognostic factors in determining breast cancer outcome. Our findings correlate with several studies showing that tumors of more than $2 \mathrm{~cm}$ size have a higher risk of recurrence than tumors of less than $2 \mathrm{~cm}$ size [24] [25].

All study patients $(n=102)$ developed metastases after completion of treatment and during follow up. The median time for development of recurrence was 17.9 months. This correlates with many series that $70 \%$ of recurrences occur in the initial 3 years after surgery with a peak at $1-2$ years' post-surgery [26]. The most common initial metastatic site was bone/soft tissue, constituting $40.2 \%$ of studied cases. This proportion is very similar to that reported by Dawood et al. and Andre et al., where bone/soft tissue metastases (non-visceral) were seen in $32 \%-46 \%$ of primary breast cancer patients on presentation [23] [27].

The median DFS after surgery was 17.88 months, while the median OS was 37.9 months. In our study, univariate analysis has shown that prognostic factors affecting DFS were tumor grade, tumor size, number of positive axillary nodes and ER/PR status. All these variables with $\mathrm{P}$ value of less than 0.5 on univariate analysis for DFS were further analyzed using multivariate analysis and factors found to be significant were tumor grade and number of positive axillary lymph nodes.

Tumor size is a widely recognized prognostic factor for breast cancer and is included in international treatment recommendations. Regarding correlation of tumor size and DFS, tumors of more than $5 \mathrm{~cm}$ in size had the lowest median time of 10.7 months as compared to those with $2-5 \mathrm{~cm}$ and less than $2 \mathrm{~cm}$, both having median times of 18.7 months. Tumors of more than $5 \mathrm{~cm}$ have the highest risk of metastasis followed by $2-5 \mathrm{~cm}$ and $<2 \mathrm{~cm}$ tumors respectively [24] [28] [29] [30]. Carter et al. has shown that increase in tumor size is directly associated with decrease in survival regardless of lymph node status [24].

Axillary lymph node involvement has been demonstrated to be the single most significant predictor of DFS and OS. Furthermore, there is a direct correlation between the number of involved axillary nodes and the risk for recurrence with distant metastasis [5] [6] [7]. Fisher et al. have demonstrated that increase 
in the number of axillary lymph nodes is associated with decrease in DFS. In the present study, cases with equal or more than 4 positive nodes had worse DFS as compared to those with less than 4 positive nodes. Regarding tumor grade and DFS, grade 3 tumors had the lowest median time of 14.5 months as compared to combined grade 1 and 2 tumors having a median time of 18.4 months. These findings correlate with many studies which demonstrated that median time from diagnosis or treatment to development of metastasis, decreases as tumor grade increases [24] [25]. In our study, ER/PR negative tumors had worse DFS when compared to ER/PR positive tumors. The NSABP-06 trial demonstrated that ER positive tumors had better disease-free survival than those with ER-negative tumors. Univariate analysis of factors found to affect OS were age at diagnosis, tumor size, tumor grade and HER2 status, while, BMI, menopausal status, ER/PR status, presence and number of axillary lymph nodes were not statistically significant predictors of survival. Regarding tumor size and OS, tumors of more than $5 \mathrm{~cm}$ in size had the lowest overall survival than tumors less than 5 $\mathrm{cm}$. This finding correlates with many studies which demonstrated that larger tumors are associated with poor survival [24] [25] [28]. Carter et al. demonstrated that tumors of $5 \mathrm{~cm}$ or more have poor overall survival as compared to tumors of less than $5 \mathrm{~cm}$ [24]. Rosen et al. observed the relationship between tumor size and 20-year DFS and found a significant association, with a 20 -year DFS of $88 \%$ for tumors $\leq 1 \mathrm{~cm}, 72 \%$ for tumors $1.1 \mathrm{~cm}$ to $3 \mathrm{~cm}$, and $59 \%$ for tumors between $3.1 \mathrm{~cm}$ and $5 \mathrm{~cm}$ [28]. Furthermore, median time to the development of metastatic disease also reduces as tumor size increases [24] [28].

Better OS in the present study was observed in low grade than high grade tumors. Rakha et al. study demonstrated that high grade tumors have poor OS and DFS than low grade tumors [10].

In our study, tumors with no HER2/neu overexpression had better OS than those with HER2/neu overexpression. Pritchard et al. demonstrated that tumors with no HER2/neu overexpression have better survival than those with HER2/neu overexpression [31].

\section{Conclusions}

- The clinicopathological characteristics of the primary tumor are important predictors of metastases among breast cancer patients and tend to determine prognosis.

- The factors negatively affecting DFS were high grade, large tumor size, equal to or more than 4 positive axillary nodes and negative ER/PR status.

- The factors negatively affecting OS were young age at diagnosis, high grade, large tumor size and HER2 positive status.

\section{Conflicts of Interest}

The authors declare no conflicts of interest regarding the publication of this paper. 


\section{References}

[1] Ferlay, J., Soerjomataram, I., Ervic, M., Dikshit, R., Eser, S., Mathers, C., et al. (2015) Cancer Incidence and Mortality Worldwide: Sources, Methods and Major Pattern in GLOBOCAN 2012. International Journal of Cancer, 136, E359-E386. https://doi.org/10.1002/ijc.29210

[2] Hirko, K.A., Soliman, A.S., Hablas, A., Seifeldin, I.A., Ramadan, M., Banerjee, M., et al. (2013) Trends in Breast Cancer Incidence Rates by Age and Stage at Diagnosis in Gharbiah, Egypt, over 10 Years (1999-2008). Journal of Cancer Epidemiology, 2013, Article ID: 916394. https://doi.org/10.1155/2013/916394

[3] Weigel, M.T. and Dowsett, M. (2010) Current and Emerging Biomarkers in Breast Cancer: Prognosis and Prediction. Endocrine-Related Cancer, 17, R245-R262. https://doi.org/10.1677/ERC-10-0136

[4] Albertini, J.J., Lyman, G.H., Cox, C., Yeatman, T., Balducci, L., Ku, N., et al. (1996) Lymphatic Mapping and Sentinel Node Biopsy in the Patient with Breast Cancer. The Journal of the American Medical Association, 276, 1818-1822. https://doi.org/10.1001/jama.1996.03540220042028

[5] Saez, R.A., McGuire, W.L. and Clark, G.M. (1989) Prognostic Factors in Breast Cancer. Seminars in Surgical Oncology, 5, 102-110. https://doi.org/10.1002/ssu.2980050206

[6] Nemoto, T., Natarajan, N., Bedwani, R., Vana, J. and Murphy, G.P. (1983) Breast Cancer in the Medial Half; Results of the 1978 National Survey of the American College of Surgeons. Cancer, 51, 1333-1338. https://doi.org/10.1002/1097-0142(19830415)51:8<1333::AID-CNCR2820510802>3. $\underline{0 . \mathrm{CO} ; 2-\mathrm{T}}$

[7] Fisher, B., Bauer, M., Wickerham, D.L., Redmond, C.K., Fisher, E.R., Cruz, A.B., et al. (1983) Relation of the Number of Positive Axillary Nodes to the Prognosis of Patients with Primary Breast Cancer. An NSABP Update. Cancer, 52, 1551-1557. https://doi.org/10.1002/1097-0142(19831101)52:9<1551::AID-CNCR2820520902>3. $\underline{0 . \mathrm{CO} ; 2-3}$

[8] Mirza, A.N., Mirza, N.Q., Vlastos, G. and Singletary, S.E. (2002) Prognostic Factors in Node-Negative Breast Cancer: A Review of Studies with Sample Size More than 200 and Follow-Up More than 5 Years. Annals of Surgery, 235, 10-26. https://doi.org/10.1097/00000658-200201000-00003

[9] Elston, C.W. and Ellis, I.O. (1991) Pathological Prognostic Factors in Breast Cancer. I. The Value of Histological Grade in Breast Cancer: Experience from a Large Study with Long-Term Follow-Up. Histopathology, 19, 403-410. https://doi.org/10.1111/j.1365-2559.1991.tb00229.x

[10] Rakha, E.A., El-Sayed, M.E., Lee, A.H., Elston, C.W., Grainge, M.J., Hodi, Z., et al. (2008) Prognostic Significance of Nottingham Histologic Grade in Invasive Breast Carcinoma. Journal of Clinical Oncology, 26, 3153-3158. https://doi.org/10.1200/JCO.2007.15.5986

[11] Fisher, B., Redmond, C., Fisher, E.R. and Caplan, R. (1988) Relative Worth of Estrogen or Progesterone Receptor and Pathologic Characteristics of Differentiation as Indicators of Prognosis in Node-Negative Breast Cancer Patients. Findings from National Surgical Adjuvant Breast and Bowel Project Protocol B-06. Journal of Clinical Oncology, 6, 1076-1087. https://doi.org/10.1200/JCO.1988.6.7.1076

[12] Haybittle, J.L., Blamey, R.W., Elston, C.W., Johnson, J., Doyle, P.J., Campbell, F.C., Nicholson, R.I. and Griffiths, K. (1982) A Prognostic Index in Primary Breast Cancer. British Journal of Cancer, 45, 361-366. https://doi.org/10.1038/bjc.1982.62 
[13] Blamey, R.W., Ellis, I.O., Pinder, S.E., Lee, A.H.S., Macmillan, R.D., Morgan, D.A.L., et al. (2007) Survival of Invasive Breast Cancer according to the Nottingham Prognostic Index in Cases Diagnosed in 1990-1999. European Journal of Cancer, 43, 1548-1555. https://doi.org/10.1016/j.ejca.2007.01.016

[14] Galea, M.H., Blamey, R.W., Elston, C.E. and Ellis, I.O. (1992) The Nottingham Prognostic Index in Primary Breast Cancer. Breast Cancer Research and Treatment, 22, 207-219. https://doi.org/10.1007/BF01840834

[15] Balslev, I., Axelsson, C.K., Zedeler, K., Rasmussen, B.B., Carstensen, B. and Mouridsen, H.T. (1994) The Nottingham Prognostic Index Applied to 9,149 Patients from the Studies of the Danish Breast Cancer Cooperative Group (DBCG). Breast Cancer Research and Treatment, 32, 281-290. https://doi.org/10.1007/BF00666005

[16] Rakha, E.A., Soria, D., Green, A.R., Lemetre, C., Powe, D.G., Nolan, C.C., Garibaldi, J.M., Ball, G. and Ellis, I.O. (2014) Nottingham Prognostic Index Plus (NPI+): A Modern Clinical Decision-Making Tool in Breast Cancer. British Journal of Cancer, 110, 1688-1697. https://doi.org/10.1038/bjc.2014.120

[17] Kennecke, H., Yerushalmi, R., Woods, R., Cheang, M.C., Voduc, D., Speers, C.H., Nielsen, T.O. and Gelmon, K. (2010) Metastatic Behavior of Breast Cancer Subtypes. Journal of Clinical Oncology, 28, 3271-3277.

https://doi.org/10.1200/JCO.2009.25.9820

[18] DeVita, V.T., Lawrence, T.S. and Rosenberg, S.A. (2008) DeVita, Hellman and Rosenberg's Cancer: Principles and Practice of Oncology. Wolters Kluwer/Lippincott Williams \& Wilkins Publishers, Philadelphia.

[19] Gerratana, L., Fanotto, V., Bonotto, M., Bolzonello, S., Minisini, A.M., Fasola, G. and Puglisi, F. (2015) Pattern of Metastasis and Outcome in Patients with Breast Cancer. Clinical and Experimental Metastasis, 32, 125-133.

https://doi.org/10.1007/s10585-015-9697-2

[20] Soni, A., Ren, Z., Hameed, O., Chanda, D., Morgan, C.J., Siegal, G.P. and Wei, S. (2015) Breast Cancer Subtypes Predispose the Site of Distant Metastases. American Journal of Clinical Pathology, 143, 471-478. https://doi.org/10.1309/AJCPYO5FSV3UPEXS

[21] Valagussa, P., Bonadonna, G. and Veronesi, U. (1978) Patterns of Relapse and Survival following Radical Mastectomy. Analysis of 716 Consecutive Patients. Cancer, 41, 1170-1178.

https://doi.org/10.1002/1097-0142(197803)41:3<1170::AID-CNCR2820410355>3.0. CO;2-I

[22] Lee, J.B., Kim, D.H., Min, B.W., Ryu, K.W., Um, J.W., Kim, A.R., Bae, J.W. and Koo, B.H. (2001) Factors Influencing the Recurrence of Breast Cancer following Modified Radical Mastectomy. Journal of Korean Breast Cancer Society, 4, 128-135. https://doi.org/10.4048/jkbcs.2001.4.2.128

[23] Dawood, S., Broglio, K., Ensor, J., Hortobagyi, G.N. and Giordano, S.H. (2010) Survival Differences among Women with de novo Stage IV and Relapsed Breast Cancer. Annals of Oncology, 21, 2169-2174. https://doi.org/10.1093/annonc/mdq220

[24] Carter, C.L., Allen, C. and Henson, D.E. (1989) Relation of Tumor Size, Lymph Node Status and Survival in 24,740 Breast Cancer Cases. Cancer, 63, 181-187. https://doi.org/10.1002/1097-0142(19890101)63:1<181::AID-CNCR2820630129>3.0 . $\mathrm{CO} ; 2-\mathrm{H}$

[25] Giuliano, A.E., Kirgan, D.M., Guenther, J.M. and Morton, D.L. (1994) Lymphatic Mapping and Sentinel Lymphadenectomy for Breast Cancer. Annals of Surgery, 220, 391-401. https://doi.org/10.1097/00000658-199409000-00015 
[26] Arriagada, R., Lê, M.G., Guinebretière, J.M., Dunant, A., Rochard, F. and Tursz, T. (2003) Late Local Recurrences in a Randomised Trial Comparing Conservative Treatment with Total Mastectomy in Early Breast Cancer Patients. Annals of Oncology, 14, 1617-1622. https://doi.org/10.1093/annonc/mdg452

[27] Andre, F., Slimane, K., Bachelot, T., Dunant, A., Namer, M., Barrelier, A., et al. (2004) Breast Cancer with Synchronous Metastases: Trends in Survival during a 14-Year Period. Journal of Clinical Oncology, 22, 3302-3308.

https://doi.org/10.1200/JCO.2004.08.095

[28] Rosen, P.P., Groshen, S., Kinne, D.W. and Norton, L. (1993) Factors Influencing Prognosis in Node-Negative Breast Carcinoma: Analysis of 767 T1N0M0/T2N0M0 Patients with Long-Term Follow-Up. Journal of Clinical Oncology, 11, 2090-2100. https://doi.org/10.1200/JCO.1993.11.11.2090

[29] Page, D.L. (1991) Prognosis and Breast Cancer. Recognition of Lethal and Favorable Prognostic Types. The American Journal of Surgical Pathology, 15, 334-349. https://doi.org/10.1097/00000478-199104000-00002

[30] Le Doussal, V., Tubiana-Hulin, M., Friedman, S., Hacene, K., Spyratos, F. and Brunet, M. (1989) Prognostic Value of Histologic Grade Nuclear Components of Scarff-Bloom-Richardson (SBR). An Improved Score Modification Based on a Multivariate Analysis of 1262 Invasive Ductal Breast Carcinomas. Cancer, 64, 1914-1921. https://doi.org/10.1002/1097-0142(19891101)64:9<1914::AID-CNCR2820640926>3. $\underline{0 . \mathrm{CO} ; 2-\mathrm{G}}$

[31] Pritchard, K., O’Malley, F.A., Andrulis, I., Shepherd, L.E., Tu, D., Levine, M.N., et al. (2002) Prognostic and Predictive Value of HER2/neu in a Randomized Trial Comparing CMF to CEF in Premenopausal Women with Axillary Lymph Node Positive Breast Cancer. Proceedings of the American Society of Clinical Oncology, 21, 42a. 